\title{
O INSTITUCIONALISMO NO CAMPO DAS TEORIAS DA ORGANIZAÇÃO: UMA ANÁLISE EM MANUAIS DIDÁTICOS DE ADMINISTRAÇÃO
}

THE INSTITUCIONALISM IN THE FIELD OF ORGANIZATIONTHEORIES: AN

ANALYSIS IN DIDACTIC MANAGEMENT MANUALS

Recebimento: 20/02/2018 - Aceite: 10/09/2018 - Publicação: 31/01/2019

Processo de Avaliação: Double Blind Review

Katia Katsumi Arakaki ${ }^{1}$

Doutoranda em Administração

Universidade Federal de Mato Grosso do Sul

katiakatsum.arakaki@gmail.com

Luisa Rhoden Rech

Doutoranda em Administração

Universidade Federal de Mato Grosso do Sul

luisarhodenrech@gmail.com

Elcio Gustavo Benini

Doutor em Educação

Universidade Federal de Mato Grosso do Sul

elciobenini@yahoo.com.br

\section{RESUMO}

Este trabalho teve como objeto de estudo o institucionalismo no campo das teorias organizacionais. Seu objetivo foi analisar como o institucionalismo, enquanto arcabouço teórico, tem sido abordado e transmitido por meio de manuais didáticos. Para realizar a análise e comparação dos manuais, utilizou-se a técnica de análise de conteúdo, por meio da construção de categorias e subcategorias, quais sejam: delimitação da abordagem e qualidade das referências; dimensão histórico-concreto; dimensão político-ideológico; dimensão epistemológica, ontológica e gnosiológica e dimensão teórica. A conclusão resultante foi que a Teoria Institucional é discutida em ambos manuais analisados, sendo um elemento importante para o bom desempenho e eficiência organizacional, apesar da discussão de menor profundidade em relação à crítica e a epistemologia da pesquisa, em um dos manuais. Diante da relevância do assunto é importante que os manuais apontem para essa discussão no sumário da obra visando maior visibilidade e facilidade de acesso.

Palavras-Chaves: Institucionalismo; Teorias da Organizações; Manuais didáticos.

\footnotetext{
${ }^{1}$ Autor para correspondência: Cidade Universitária, Av. Costa e Silva - Pioneiros, MS, Brasil. 79070900
}

Revista ENIAC Pesquisa, Guarulhos (SP), V.8, n.1, jan.- jun. 2019. 


\section{ABSTRACT}

This work had as object of study the institutionalism in the field of organizational theories. Its objective was to analyze how institutionalism, as a theoretical framework, has been approached and transmitted through textbooks. To perform the analysis and comparison of the manuals, the technique of content analysis was used, through the construction of categories and subcategories, which are: delimitation of the approach and quality of references; historical-concrete dimension; political-ideological dimension; epistemological, ontological and gnosiological dimension and theoretical dimension. The resulting conclusion was that the Institutional Theory is discussed in both handbooks analyzed, being an important element for the good performance and organizational efficiency, despite the discussion of less depth in relation to the criticism and the epistemology of the research, in one of the manuals. Given the relevance of the subject it is important that the manuals point to this discussion in the summary of the work aiming at greater visibility and ease of access.

Keywords: Institutionalism; Theories of Organizations; Instructional manuals.

\section{INTRODUÇÃO}

Instituições são regras capazes de sustentar relações políticas, econômicas e sociais. Elas podem ser formais, representadas por leis, constituições e direitos de propriedade ou informais tais como costumes e tradições (NORTH, 1991).

O institucionalismo clássico possuía interfaces com diversas áreas do conhecimento, como na ciência política, voltada à função do Estado, da constituição e das leis e na economia, envolvendo o mercado financeiro. Com efeito, é perceptível o protagonismo de Veblen (18571929) para a difusão do institucionalismo na economia, cujo amplo conhecimento fez com que estas discussões avançassem por diversas disciplinas (DA SILVA, 2012). Este autor destaca ainda que as instituições foram construídas no decorrer da história constituindo-se como um elemento explicativo da ação social (DA SILVA, 2012).

O institucionalismo, enquanto arcabouço teórico, é objeto complexo, o que leva a um panorama de pesquisas bastante diversificado e uma carência de conhecimentos sobre a temática (WILLIAMSON, 2000), que é foco de estudos em várias disciplinas (PEREIRA, 2007; DA SILVA, 2012), ocasionando a necessidade de uma teoria unificada sobre a temática (WILLIAMSON, 2000).

Dentro do contexto das organizações, a existência de um ambiente institucional forte é fundamental (WILLIAMSON, 1993). Alguns autores têm abordado a importância destas teorias para o desenvolvimento da confiança entre as partes interessadas na transação

Revista ENIAC Pesquisa, Guarulhos (SP), V.8, n.1, jan.- jun. 2019. 
(WILLIAMSON, 1993; ZYLBERSZTAJN; ZUURBIER, 1999;BACHMANN; INKPEN, 2011).

Em uma visão macro, as instituições podem ajudar a superar crises mundiais através da potencialização da confiança entre os agentes e, em uma visão micro, a ação individual ou coletiva anexada ao ambiente institucional onde o relacionamento ocorre, pode gerar uma esfera confiável com relação ao comportamento futuro dos agentes envolvidos nessas condições (BACHMANN; INKPEN, 2011).

Esta confiança está associada também à capacidade dos atores coletivos de fazerem cumprir as disposições institucionais no ambiente de negócios, funcionando como um fiador pessoal. Nesse contexto, as estruturas institucionais capazes aumentar a confiança são por exemplo a regulamentação legal, códigos de conduta profissional, reputação corporativa, normas dos contratos de trabalho, entre outras normas formais e informais de comportamento (BACHMANN; INKPEN, 2011).

Tendo em vista a importância das instituições no ambiente organizacional, objetivouse com esta pesquisa analisar dois manuais de Teoria Geral da Administração (TGA) no que se refere à discussão do institucionalismo dentro das organizações, respondendo a seguinte questão: Como a abordagem do institucionalismo tem sido ensinada e transmitida nos manuais didáticos de TGA? Assim, o objetivo deste trabalho foi analisar como o institucionalismo, enquanto arcabouço teórico, tem sido abordado e transmitido por meio de manuais didáticos.

No que diz respeito à produção científica sobre a ferramenta manual didático, é importante ressaltar que alguns estudos já foram realizados no campo dos estudos organizacionais. Tanto Pimentel et al (2006) em "Espelho, espelho meu, me diga que teoria uso eu" quanto Lopes (2007) em "Manuais de administração: contribuições e limitações no ensino de teorias em organizações" apresentaram críticas importantes sobre a utilização de manuais didáticos, ponderando a necessidade da utilização de obras clássicas. No que diz respeito ao ensino do institucionalismo por meio de manuais didáticos, nenhum esforço parece ter sido feito.

Assim, o texto que se segue está estruturado da seguinte forma: a seção seguinte apresenta a abordagem da Teoria Institucional: contexto, gênese, objetivos e legados; seguido do método de escolha dos manuais; a próxima seção do ensino da abordagem institucionalista nos manuais de administração no Brasil; a análise crítica da abordagem e dos manuais de administração e considerações finais.

Revista ENIAC Pesquisa, Guarulhos (SP), V.8, n.1, jan.- jun. 2019. 


\section{ABORDAGEM DA TEORIA INSTITUCIONAL: CONTEXTO, GENESE, OBJETIVOS E LEGADOS}

Segundo March (2013), a origem do estudo organizacional pode ser encontrada nas publicações do campo da psicologia e sociologia, como também nas áreas de ciência política e economia. O autor relata publicações anteriores a Segunda Guerra Mundial como de Barnard (1938) e de Roethlisberger e Dickson (1939); e ainda, aquelas que, também elaboradas antes da guerra, continuaram a ser publicadas e citadas ao longo dos 30 anos ulteriores (e.g. Max Weber sobre burocracia de 1940 e Mary Parker Follettapud MARCH, 2013).

Dentre outras publicações de impacto na ciência organizacional, obras de Gulick e Urwick (1937) e de Simon (1945/1957) como “Administrative Behavior" e March e Simon (1958), também se destacam na área pela repercussão em publicações e citações (MARCH, 2013).

Os primeiros indícios das instituições, apontados na sociologia, surgiram em pesquisas das escolas norte americanas sobre as organizações como problemas sociais de desigualdade social (e.g. PARK, 1922; THOMAS; ZANANIECKI, 1927apud TOLBERT; ZUCKER, 2010). É possível ainda encontrar elementos das características típicas da organização nos escritos sobre a burocratização e a burocracia de Saint-Simon, quando trata da racionalização do processo central e da estrutura (COURPASSON; REED, 2004).

Merton (1948) deu visibilidade à perspectiva funcionalista das pesquisas empíricas na qual envolvia as organizações como atores sociais independentes, capazes de criar novas estruturas institucionais, participar e ser participante das dinâmicas da mudança social (TUNER, 1974 apud TOLBERT; ZUCKER, 2010).

Segundo Tolbert e Zucker (2010), as perspectivas institucionais da ciência organizacional foram fortemente marcadas pela publicação do artigo clássico de Meyer e Rowan (1977), que tratou de aspectos das estruturas organizacionais formais em relação às regras institucionais, que funcionam como mitos e legitimadores das atividades do ambiente sejam por coordenação e controle ou confiança e boa-fé. A partir do marco de uma teoria institucional, pesquisas com esta abordagem analisam a existência de institucionalização em diversas estruturas produtivas (TOLBERT; ZUCKER, 2010).

Alguns autores reconhecem a complexidade do conceito de instituição, devido aos diversos empregos da palavra (CONCEIÇÃO, 2002; PAULON, 2009), mas apontam que a etimologia da palavra "instituição", que advém do latim institutio, indica a inovação em

Revista ENIAC Pesquisa, Guarulhos (SP), V.8, n.1, jan.- jun. 2019. 
relação ao estabelecimento de método e sistema para alcançar uma finalidade (DA SILVA; DOS SANTOS; DOS SANTOS, 2017).

No campo da psicologia, Bleger e Kaës $(1988 ; 1991)$ distinguem as duas acepções do termo, sendo (1) "instituição" um conjunto de normas, regras e rotinas fundamentadas em valores e funções sociais e (2) “organização" uma estrutura de funções hierárquicas limitadas por um prédio (MORETTO; TERZIS, 2010).

A multiplicidade de situações em que o termo "instituição" é usado, gera diversos conceitos e definições. Seu significado varia de acordo com o contexto em que é aplicado e a escola de pensamento em que é gerado.

De acordo com Conceição (2002), as abordagens da economia institucional se distinguem por aspectos quanto ao processo de mudança, à crítica ao pensamento neoclássico, ao processo histórico, e essencialmente pelo conflito como inerente a atividade humana. $\mathrm{O}$ autor classificou as escolas pelo campo analítico: (i) Neo-Institucionalista, (ii) Escola Francesa da Regulação e (iii) Escola Evolucionária ou Neo-schumpeteriana.

A primeira é mais próxima das ideias institucionalistas de Veblen; a segunda, se debruça nos aspectos de incorporação do processo de mudança, a exemplo do fordismo, e por fim, o legado da terceira classificação consiste no enfoque microeconômico da firma por meio da mudança e da inovação tecnológica (CONCEIÇÃO, 2002).

$\mathrm{Na}$ obra "Institutions and organizations: ideas, interests, and identities", $W$. Richard Scott (2001) apresentou a teoria institucional inicial nos aspectos da economia, ciência política e na sociologia. Por meio dos tópicos (1) Modelo Institucional de Selznick, (2) Abordagem Institucional de Parson, (3) Carnegie School, (4) Teoria Cognitiva, (5) Teoria NeoInstitucional na Economia, (6) Teoria Neo-Institucional na Sociologia e (7) Teoria NeoInstitucional na Ciência Política.

Atualmente, a complexidade do mercado, envolvendo a demanda e a exigência dos consumidores tem feito com que os agentes da cadeia produtiva clamem por uma nova lista de políticas, leis e sistemas de controle buscando atender as necessidades do mercado (CARRER; SOUZA FILHO; VINHOLIS, 2014). Neste sentido a contribuição das instituições é fundamental, pois a sua principal função é criar ordem e reduzir incertezas (NORTH, 1991).

Revista ENIAC Pesquisa, Guarulhos (SP), V.8, n.1, jan.- jun. 2019. 


\section{METODOLOGIA}

Para alcançar o objetivo deste trabalho e analisar como a abordagem do institucionalismo tem sido tratada em manuais didáticos de TGA, ficaram estabelecidos critérios para escolha do manual de TGA.

Assim, atentando-se a um rigor metodológico, foram selecionados provisoriamente e por critérios de conveniência e acessibilidade alguns manuais de TGA disponível na biblioteca da Universidade Federal, apresentados na Tabela 1:

Tabela 1: Manuais selecionados

\begin{tabular}{|c|c|c|}
\hline Manual & Autores/Organizadores & Ano \\
\hline Administração: Teorias e Processos & Caravantes; Caravantes e Kloeckner & $\begin{array}{l}2005 \\
2010\end{array}$ \\
\hline Teoria Geral da Administração & Motta e Vasconcelos & 2013 \\
\hline Introdução à Administração & Chiavetto & \\
\hline Teoria Geral da Administração & Maximiano & 2004 \\
\hline $\begin{array}{ll}\text { Handbook de } & \text { Estudos } \\
\text { Organizacionais }- \text { Vol. 1 } & \end{array}$ & Caldas; Fachin e Fischer & 2010 \\
\hline
\end{tabular}

Foram então, analisados os sumários dos manuais (Tabela 1), objetivando encontrar tópicos específicos a respeito da temática em estudo. Apenas um dos cinco manuais possuía capítulos abordando a Teoria Institucional, o Handbook de Estudos Organizacionais (Vol. 1), sendo que este foi então escolhido como manual base para a análise. Posteriormente, foi selecionado o manual Teoria Geral da Administração (MOTTA; VASCONCELOS, 2013), que, dentre os todos os analisados, demonstrou maior potencial para atender aos objetivos da pesquisa, tanto devido ao ano de publicação, que foi o mais atual dentre os analisados quanto ao potencial de conteúdos apresentados.

Desta forma, no manual base foram contemplados dois capítulos para análise, são eles o capítulo seis, intitulado "A institucionalização da Teoria Institucional” de autoria de Pamela S. Tolbert e Lynne G. Zucker e o sete "Nota técnica: A Teoria Institucional" de autoria de Clóvis L. Machado-Da-Silva e Sandro A. Gonçalves. Vale ressaltar que o Handbook de Estudos Organizacionais é um manual que contempla diversas autorias, onde cada um de seus capítulos é redigido por determinados autores, portanto os conceitos apresentados retratam a ideia daqueles autores podendo haver divergências quanto a algumas concepções ou denominações em outros capítulos do livro.

Revista ENIAC Pesquisa, Guarulhos (SP), V.8, n.1, jan.- jun. 2019. 
Já no Manual do Motta e Vasconcelos (2013a) não foi identificado um capítulo para tratar da institucionalização, contudo os autores abordam a temática em um item que compõe o capítulo de Teorias Ambientais (capítulo 13), especificamente o Neo-institucionalismo (item 13.6). Assim, foi analisado o item específico do capítulo sobre o Neo-Institucionalismo, pois poderia conter elementos sobre a sua origem e demais desdobramentos da abordagem.

Para realizar a análise e comparação dos manuais, utilizou-se a técnica de análise de conteúdo (BARDIN, 2011), por meio da construção de categorias e subcategorias. Assim, foram eleitas 4 dimensões de análises, sendo estas divididas em eixos e/ou subcategorias, quais sejam: delimitação da abordagem e qualidade das referências (1); dimensão históricoconcreto(2); dimensão político-ideológico(3); dimensão epistemológica, ontológica e gnosiológica(4) e dimensão teórica (5).

\section{O ENSINO DA ABORDAGEM INSTITUCIONALISTA NOS MANUAIS DE ADMINISTRAÇÃO NO BRASIL}

A obra escolhida como base para análise foi a versão brasileira do "Handbook de Estudos Organizacionais”, organizado por Miguel Caldas, Roberto Fachin e Tânia Fischer, cujo propósito é apresentar uma alternativa, bem como uma crítica ao mainstream da pesquisa funcionalista e neopositivista da ciência organizacional.

Sobre a obra, Cunha (1997) evidencia o dinamismo em relação à diversidade de temas, pensamentos, culturas e origens geográficas dos autores, enriquecendo os trabalhos em teoria organizacional, inclusive para a psicologia. Bertero (2005) não considera a obra propriamente um "manual", contudo admite que seus aspectos pedagógicos permitem reflexões profundas sobre o tema, caracterizando-a como um instrumento para todos profissionais envolvidos com a área organizacional.

A outra obra escolhida como objeto de análise é o manual acadêmico "Teoria Geral da Administração" dos autores Fernando C. Prestes Motta e Isabella Fernando Gouveia de Vasconcelos.

Ana Paula Paes de Paula (2005) aponta que, tradicionalmente, Prestes Motta incluía noções da sociologia advindas da abordagem funcionalista, com finalidade instrumental à análise da realidade social ou abordagem clássica da ciência política nas análises das organizações, com a associação do comportamento dos indivíduos, grupos ou organizações ao modelo burocrático (weberiana) ou aos condicionantes socioeconômicos (marxismo). Ao

Revista ENIAC Pesquisa, Guarulhos (SP), V.8, n.1, jan.- jun. 2019. 
longo de sua carreira, Prestes Motta incluiu a visão crítica da burocracia ao longo do tempo, bem como da própria teoria das organizações (BRESSER-PEREIRA, 2003).

Na primeira categoria de análise, quanto à delimitação da abordagem e qualidade das referências do Handbook de Estudos organizacionais foi possível identificar que os principais autores referenciados e seu respectivo número de citações foram: Zucker (30); Tolbert (21); Meyer (17); Scott (14); Rowan (11); Luckmann (9); Berger (8); DiMaggio (6); Barley (5); Strang (5); Powell (3); Jennings (3); Fligstein (3); Dobbin (3); Slancik (2); Peng (2);Schutz (2); Winter (2); Zhou (2); Edelman (2); Darby (2); Davis (2); Brewer (2); Baron (2); Johnson (2); Mezias (2); Miner (2); Nelson (2) e os demais apareceram apenas uma vez.

Já no manual "Teoria Geral da Administração" dos autores Motta e Vasconcelos (2013b), verifica-se a existência de segmentação da abordagem do neo-institucionalismo, o destaque das referências se dá para os seguintes autores: Meyer (12); Rowan (9); Scott (7); Vasconcelos, I. (6); DiMaggio (4); Machado-da-Silva (4); Berger (4); Luckmann (4); Vasconcelos, F (4) e Powell (3). Os autores Bourdieu; Da Matta; Dias; Fonseca; Loiola; Misoczky; Velho; Wood Jr. e Zucker foram citados duas vezes no item sobre Neoinstitucionalismo.

Quanto às citações apresentadas no item 13.6 da obra TGA, verifica-se o total de 89 citações, sendo: duas citações diretas, com destaque aos autores Meyer e Scott, 85 citações indiretas principalmente de Meyer e Rowan, e duas citações do tipo apud de Bourdie. O Gráfico 1 apresenta os autores mais citados e que foram apontados em ambas as obras:

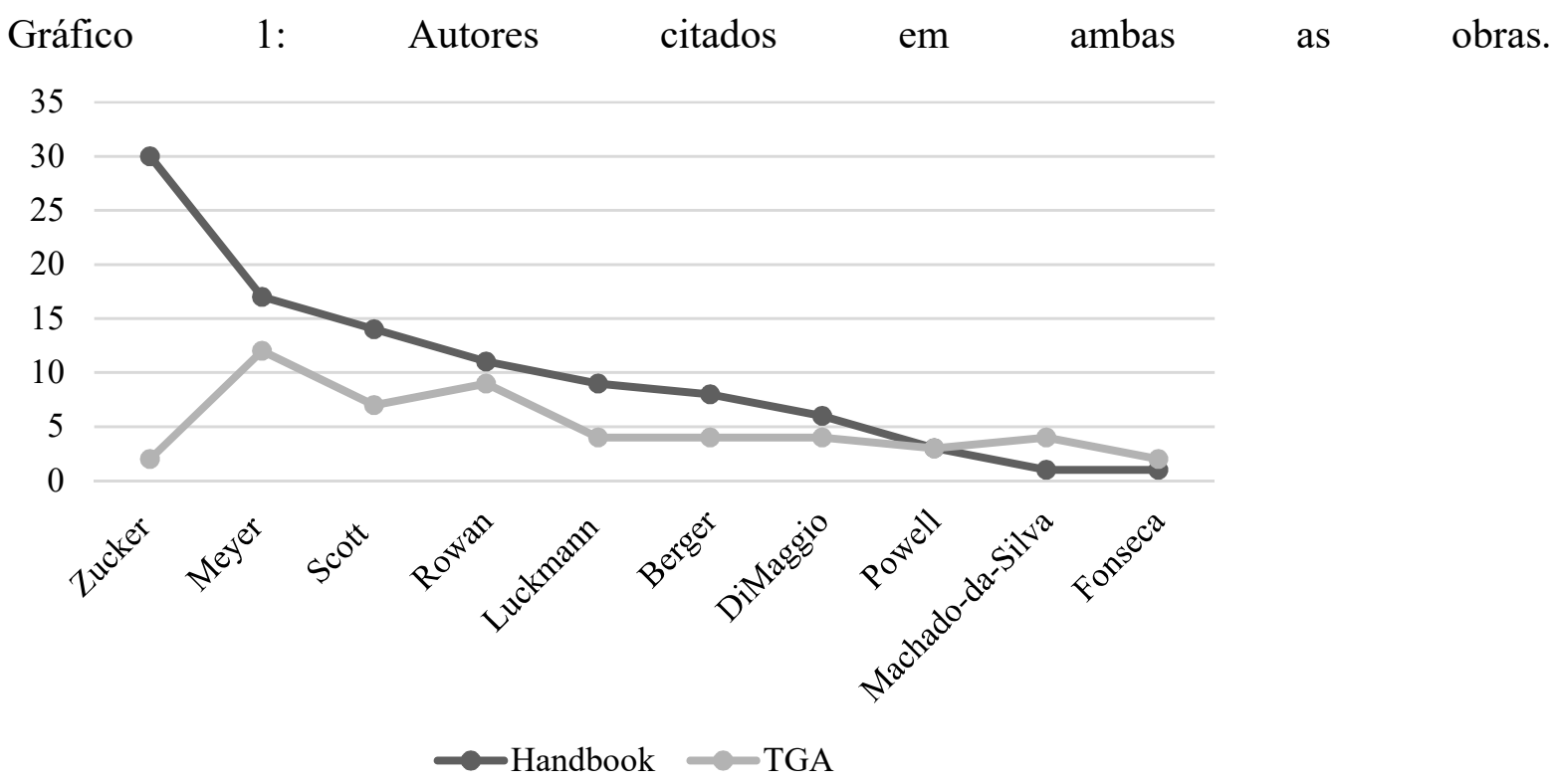

Fonte: Elaborados pelos autores a partir dos dados (2018).

Revista ENIAC Pesquisa, Guarulhos (SP), V.8, n.1, jan.- jun. 2019. 
Destacamos a relevância que tiveram os autores Meyer, Scott, Rowan, Luckmann, Berger e DiMaggioque em ambas as obras analisadas. O Quadro 1 apresenta a análise dos dois manuais quanto às referências.

Quadro 1 - Delimitação da abordagem e qualidade das referências.

\begin{tabular}{|c|c|c|}
\hline Eixos analisados & $\begin{array}{c}\text { Handbook de Estudos } \\
\text { Organizacionais - Vol. } 1\end{array}$ & Teoria Geral da Administração \\
\hline $\begin{array}{l}\text { Principais autores enquadrados } \\
\text { na abordagem }\end{array}$ & $\begin{array}{l}\text { Zucker; Tolbert; Meyer; Scott; } \\
\text { Rowan; Luckmann; Berger; } \\
\text { DiMaggio; Barley; Strang. }\end{array}$ & $\begin{array}{c}\text { Meyer; Rowan; Scott; } \\
\text { Vasconcelos e Vasconcelos; } \\
\text { DiMaggio; Machado-da-Silva; } \\
\text { Berger e Luckmann. }\end{array}$ \\
\hline $\begin{array}{l}\text { Autor de maior destaque e/ou de } \\
\text { maior evidência no manual }\end{array}$ & Lynne G. Zucker & Meyer e Rowan \\
\hline Número de citações diretas & 16 & 2 \\
\hline $\begin{array}{l}\text { Autor com maior número de } \\
\text { citações diretas }\end{array}$ & W. Richard Scott & Meyer e Scott \\
\hline Número de citações indiretas & 116 & 85 \\
\hline $\begin{array}{l}\text { Autor com o maior número de } \\
\text { citações indiretas }\end{array}$ & Lynne G. Zucker & Meyer e Rowan \\
\hline $\begin{array}{l}\text { Número de citações do tipo } \\
\text { apud }\end{array}$ & 3 & 2 \\
\hline $\begin{array}{l}\text { Autor com o maior número de } \\
\text { citações usadas como apud }\end{array}$ & Barley e Tolbert (1997) & Bourdieu \\
\hline
\end{tabular}

Fonte: Elaborado pelos autores a partir dos dados (2018).

Na obra "Handbook de Estudos Organizacionais" foi identificado um possível viés pois o autor de maior destaque nas citações de Lynne G. Zucker foi também um dos autores responsáveis pelo capítulo seis da obra analisada, foco desta pesquisa. Esta mesma obra também foi identificada com um maior número de citações tanto direta quanto indireta em relação ao manual Teoria Geral da Administração.

A próxima categoria de análise é a dimensão histórico-concreta, sendo segmentados em eixos como a relação com o contexto econômico (1), tecnologia existente (2) instituições concretas (3), conforme apresentado pelo Quadro 2.

Revista ENIAC Pesquisa, Guarulhos (SP), V.8, n.1, jan.- jun. 2019. 
Quadro 2 -Dimensão histórico-concreto apresentada

\begin{tabular}{|c|c|c|}
\hline Eixos analisadas & $\begin{array}{c}\text { Handbook de Estudos } \\
\text { Organizacionais - Vol. } 1 \\
\end{array}$ & Teoria Geral da Administração \\
\hline $\begin{array}{l}\text { Relação com o contexto } \\
\text { econômico }\end{array}$ & $\begin{array}{l}\text { Ambiente aberto, relação direta } \\
\text { de dependência das organizações } \\
\text { para com a sociedade. }\end{array}$ & $\begin{array}{l}\text { Depedência da adequação das } \\
\text { organizações aos padrões } \\
\text { institucionalizados no setor. }\end{array}$ \\
\hline $\begin{array}{l}\text { Relação com a tecnologia } \\
\text { existente }\end{array}$ & $\begin{array}{l}\text { Mudanças tecnológicas afetam } \\
\text { juntamente com a legislação e as } \\
\text { forças de mercados, o processo de } \\
\text { inovação nas organizações (início } \\
\text { do processo de } \\
\text { institucionalização). }\end{array}$ & $\begin{array}{l}\text { A tecnologia é apresentada como } \\
\text { uma "solução possível", mas age e } \\
\text { representa a a realidade } \\
\text { predominante em uma organização. }\end{array}$ \\
\hline $\begin{array}{l}\text { Relação com as instituições } \\
\text { concretas }\end{array}$ & $\begin{array}{l}\text { As estruturas formais têm tanto } \\
\text { propriedades simbólicas como } \\
\text { capacidade de gerar ação e são } \\
\text { essenciais para a sobrevivência e } \\
\text { sucesso organizacional (produto } \\
\text { do processo } \\
\text { institucionalização). }\end{array}$ & $\begin{array}{l}\text { Autoridade das } \text { instituições } \\
\text { concretas ou setores institucionais } \\
\text { em relação às organizações, } \\
\text { devendo estas se conformar } \\
\text { àquelas. }\end{array}$ \\
\hline
\end{tabular}

Fonte: Elaborado pelos autores a partir dos dados (2018).

Tratando-se do contexto econômico os autores do Handbook descreveram uma relação de dependência das organizações para com a sociedade, ou seja, a existência de um impacto direto do ambiente externo no desempenho das organizações, já na abordagem neoinstitucional do manual de TGA, a organização é dependente da conformidade com o modelo institucionalizado. Assim, quanto maior o grau de conformidade ou adequação da organização às regras institucionais, maiores são as chances de sobrevivência e sucesso econômico.

$\mathrm{Na}$ discussão a respeito da tecnologia existente, o Handbook indica uma relação entre a tecnologia, a legislação e as forças de mercado em benefício da inovação dentro das organizações o que é visto como o início do seu processo de institucionalização.

Motta e Vasconcelos (2013b) relacionam elementos como estruturas organizacionais, padrões culturais e tecnologias como uma forma de representação objetiva que favorecem interesses de poder de grupos dominantes. Assim, a abordagem institucional se relaciona com a tecnologia existente como um "mito" ou "modelo" capaz de influenciar a ação de indivíduos e organizações, por meio de legitimidade, reconhecimento e recursos.

Em contrapartida a isso no Handbook as instituições concretas são entendidas como o produto do processo de institucionalização e elas é que são vistas com capazes de gerar ação, sendo essenciais à sobrevivência organizacional. Já Motta e Vasconcelos (2013b) referenciam Scott e Meyer (1991) e expõem a definição de setores institucionais como os setores sociais capazes de sustentar seus interesses por meio de regras e normas, havendo dependência das organizações a essas instituições concretas para angariar sucesso e legitimidade no ambiente.

Revista ENIAC Pesquisa, Guarulhos (SP), V.8, n.1, jan.- jun. 2019. 
A terceira categoria de análise é a dimensão político-ideológico da abordagem institucionalista, quatro principais eixos foram observados: conflito entre administração e administrados (1), conflito entre capital e trabalho (2), relação com o sistema capitalista (3) e formas de controle e poder (4) como apresentado no Quadro 3.

Quadro 3 - Dimensão político-ideológico apresentada

\begin{tabular}{|c|c|c|}
\hline Eixos analisadas & $\begin{array}{c}\text { Handbook de Estudos } \\
\text { Organizacionais - Vol. } 1\end{array}$ & Teoria Geral da Administração \\
\hline $\begin{array}{l}\text { Conflito entre administração e } \\
\text { administrados }\end{array}$ & $\begin{array}{l}\text { Gerar reconhecimento da } \\
\text { existência de um padrão de } \\
\text { insatisfação ou fracasso de um } \\
\text { determinado grupo e apresentar a } \\
\text { solução e tratamento/ Resistencia a } \\
\text { aceitação normativa. }\end{array}$ & $\begin{array}{l}\text { Reconhecimento do conflito de } \\
\text { interesses por considerar a } \\
\text { organização como uma arena } \\
\text { política e pelas buscas estratégicas } \\
\text { de incorporação de modelos } \\
\text { cognitivos. }\end{array}$ \\
\hline Conflito entre capital e trabalho & $\begin{array}{l}\text { Estruturas negligenciadas, sem } \\
\text { aplicação rígida, levam a um } \\
\text { sistema de coordenação } \\
\text { defeituoso, violando normas e } \\
\text { desencadeando tecnologias e } \\
\text { sistemas pouco eficientes. }\end{array}$ & $\begin{array}{l}\text { Não discussão explícita do conflito } \\
\text { entre capital e trabalho. Expressa } \\
\text { os conflitos entre interesses } \\
\text { expressados pelos indivíduos na } \\
\text { disputa pelo poder. }\end{array}$ \\
\hline Relação com sistema capitalista & Não há referência. & $\begin{array}{l}\text { É dado como posto e não é } \\
\text { questionado. }\end{array}$ \\
\hline Formas de controle e poder & $\begin{array}{l}\text { Indivíduos aceitam normas sociais } \\
\text { sem qualquer reflexão ou } \\
\text { resistência comportamental e sem } \\
\text { questionamentos, principalmente } \\
\text { quando elas são eficientes e } \\
\text { racionais, geram aceitação social. }\end{array}$ & $\begin{array}{l}\text { Por estratégias de adoção de } \\
\text { modelos normativos e estruturais: } \\
\text { a coerção, a normalização, } \\
\text { a indução e o mimetismo } \\
\text { organizacional. }\end{array}$ \\
\hline
\end{tabular}

Fonte: Elaborado pelos autores a partir dos dados (2018).

O Handbook identifica que o conflito entre administradores e administrados pode ocorrer devido à falta de entendimento ou comunicação entre as partes, onde os administrados seguem normas institucionalizadas rígidas ou mostram resistência em aceitar novas regras, neste ponto aqueles que detém o poder precisam ser flexíveis e buscar soluções, reconhecendo a melhor forma de lidar e readequar seus padrões e normas.

Motta e Vasconcelos (2013b) reservam um item específico (13.6.3) para tratar das formas de incorporação de modelos cognitivos pelas organizações. Ressaltam que os dirigentes usam de formas normativas e estruturais em suas ações para institucionalizar seus interesses nas organizações. Da mesma forma que no Handbook o manual de TGA, reconhece o conflito existente entre administração e administrados, inclusive de forma colateral entre os próprios administrados, neste pondo Motta e Vasconcelos (2013b) consideraram focar na estratégia de criação e implementação de modelos predominantes.

Revista ENIAC Pesquisa, Guarulhos (SP), V.8, n.1, jan.- jun. 2019. 
O conflito entre capital e trabalho é entendido no Handbook como a desatenção que ocorre em relação as estruturas e ao sistema, quando estas não recebem o devido cuidado o capital empregado para o seu desenvolvimento e aplicação também acaba negligenciado tornando-as pouco eficientes, o que é prejudicial ao bom desempenho das organizações.

No manual TGA, a relação com o sistema capitalista não é abordada de forma expositiva, observa-se que o capitalismo é tratado como posto, inquestionável e determinante, assim, interpreta-se a relação considera um modelo econômico já institucionalizado, sustentado pelo interesse predominante. $\mathrm{Na}$ abordagem, os conflitos são relatados com pouca discussão ideológica, sem profundidade em relação ao conflito entre capital e trabalho. Os conflitos são considerados no sentido de divergência de interesses entre indivíduos que necessitam de conformidade ao sistema instituído.

Especificamente no eixo de formas de controle e poder da abordagem, o Handbook aponta para a submissão dos indivíduos as normas sociais, notadamente quando estas se mostram eficientes e plausíveis são acatadas sem reivindicações; desta forma, como já apresentado pelo manual TGA de Motta e Vasconcelos (2013b), a administração utiliza-se destas normas em prol da obediência de seus subordinados.

Quanto a este tópico o manual de TGA observa de forma categórica a apresentação e a adoção de modelos normativos e estruturais, por meio de quatro formas de institucionalização, sendo elas: a coerção, a normalização, a indução e o mimetismo organizacional.

A próxima dimensão de análise é a epistemológica, ontológica e gnosiológica, tendo quatro eixos de investigação: concepção de homem (1), relação entre sujeito e objeto no processo de conhecimento (2), procedimento metodológico atribuído (3) e técnicas que tem sido utilizadas (4) na abordagem institucionalista, como exposto no Quadro 4.

Revista ENIAC Pesquisa, Guarulhos (SP), V.8, n.1, jan.- jun. 2019. 
Quadro 4 - Dimensão epistemológica, ontológica e gnosiológica apresentada

\begin{tabular}{|c|c|c|}
\hline Eixos analisadas & $\begin{array}{c}\text { Handbook de Estudos } \\
\text { Organizacionais - Vol. } 1 \\
\end{array}$ & Teoria Geral da Administração \\
\hline Concepção de homem & $\begin{array}{l}\text { Homem age e reage no ambiente } \\
\text { social e quando suas ações que se } \\
\text { tornam habituais, criam } \\
\text { comportamentos que são adotados } \\
\text { por um grupo a fim de resolver } \\
\text { problemas recorrentes. }\end{array}$ & $\begin{array}{l}\text { Homem um ator social, com } \\
\text { racionalidades diversas, que } \\
\text { significa suas percepções da } \\
\text { realidade, de modo estratégico, } \\
\text { vinculando às regras } \\
\text { organizacionais e institucionais na } \\
\text { sociedade. }\end{array}$ \\
\hline $\begin{array}{l}\text { Relação entre sujeito e objeto no } \\
\text { processo de conhecimento }\end{array}$ & $\begin{array}{l}\text { As estruturas formais são } \\
\text { revestidas de significados } \\
\text { socialmente compartilhados, } \\
\text { possuem funções objetivas e } \\
\text { servem para informar públicos } \\
\text { internos e externos. }\end{array}$ & $\begin{array}{l}\text { Não é explicitado por uma única } \\
\text { forma, deduz-se que o } \\
\text { conhecimento é obtido por meio da } \\
\text { revelação dos valores } \\
\text { significados dos modelos } \\
\text { institucionalizados. }\end{array}$ \\
\hline $\begin{array}{l}\text { Procedimento metodológico } \\
\text { atribuído }\end{array}$ & $\begin{array}{l}\text { "A teoria institucional ainda não } \\
\text { desenvolveu um conjunto central } \\
\text { de variáveis-padrão, não tem } \\
\text { metodologia de pesquisa } \\
\text { padronizada nem tampouco } \\
\text { conjunto de métodos específicos. } \\
\text { (TOLBER; ZUCKER, 2010)" }\end{array}$ & $\begin{array}{l}\text { Apresentação expositiva com } \\
\text { enfoque explicativo; não se } \\
\text { vincula às formas e ou aos modelos } \\
\text { específicos. }\end{array}$ \\
\hline Técnicas que têm sido utilizadas & $\begin{array}{l}\text { Estudos de caso, regressão } \\
\text { múltipla, modelos longitudinais, } \\
\text { etc. }\end{array}$ & $\begin{array}{l}\text { Estudos sociotécnicos, ex. estudos } \\
\text { de caso. }\end{array}$ \\
\hline
\end{tabular}

Fonte: Elaborado pelos autores a partir dos dados (2018).

No Handbook os problemas comuns do dia-a-dia levam os indivíduos a agirem constantemente de forma a solucionar os impasses, essa ação se torna hábito e gera comportamentos comuns em um grupo, assim o homem é visto como um ser que interage com o meio e cria seus próprios costumes. Já no manual TGA, os autores mostram a sucessão da concepção de homem do homo economicus, na qual se baseia na racionalidade absoluta e na autonomia do homem em busca da maximização dos resultados; para o homem ator social, que formula estratégias adequadas aos significados e aos padrões já institucionalizados.

No item da relação entre sujeito e objeto no processo do conhecimento os autores do primeiro manual acreditam que este se dá quando os significados e ações são compartilhados entre os indivíduos buscando as melhores soluções, desta forma, mantendo os públicos internos e externos bem informadas. Com relação aos procedimentos metodológicos os autores alertam que estes não possuem uma fórmula padrão, ainda são bastante heterogêneos, o que leva a utilização de um variado leque de técnicas para o estudo da teoria institucional.

Revista ENIAC Pesquisa, Guarulhos (SP), V.8, n.1, jan.- jun. 2019. 
Para Motta e Vasconcelos (2013a) expõe na introdução da obra que a relação entre sujeito e objeto no processo de conhecimento e o procedimento metodológico atribuído às pesquisas deneo-institucionalistas, possuem uma abordagem classificada com o enfoque póscontingencial devido sua abordagem transversal e ambiental. No item do capítulo 13, que trata do neo-institucionalismo, os autores se aprofundaram na natureza epistemológica da teoria. Contudo, apresentam o conteúdo da abordagem por meio de exemplos de casos empíricos, mostrando que o enfoque da teoria é a conformidade à modelos institucionais, independente de formais e quais sejam tais modelos.

Por fim, na última dimensão de análise, os aspectos teóricos apresentados são explorados pelos eixos: concepção de organização (1), sistema de incentivo (2), resultados a ser alcançados (3) e foco da teoria institucional (4), segue no Quadro 5.

Quadro 5 - Dimensão teórica apresentada

\begin{tabular}{|c|c|c|}
\hline Eixos analisadas & $\begin{array}{c}\text { Handbook de Estudos } \\
\text { Organizacionais - Vol. } 1\end{array}$ & TGA \\
\hline Concepção de organização & $\begin{array}{llr}\text { São caracterizadas } & \text { por } \\
\text { propriedades como } & \text { autoridade } \\
\text { hierárquica, período } & \text { de vida } \\
\text { potencialmente } & \text { ilimitado, } \\
\text { responsabilidades } & \text { legais } \\
\text { específicas. } & \end{array}$ & $\begin{array}{l}\text { Organização passa como sistema } \\
\text { racional e universo cognitivo para } \\
\text { se tornar uma arena social } \\
\text { (Fonseca e Machado-da-Silva, } \\
\text { 2001) }\end{array}$ \\
\hline Sistema de incentivo & $\begin{array}{l}\text { Aumentar a competitividade, } \\
\text { monitoramento dos concorrentes, } \\
\text { visando avaliar os efeitos } \\
\text { vivenciados por essas para tomar a } \\
\text { decisão da adoção. }\end{array}$ & $\begin{array}{l}\text { Modelos psicossociais de } \\
\text { incentivos, voltados para a gestão } \\
\text { e o controle estratégicos do } \\
\text { homem como ator social e da } \\
\text { organização como arena política } \\
\text { (Silva, 2001; Motta et al.,1995) }\end{array}$ \\
\hline Resultados a ser alcançados & $\begin{array}{l}\text { Sedimentação de estruturas, } \\
\text { instituições fortes, capazes de } \\
\text { aumentar a transmissão de ações, } \\
\text { mantendo-as ao longo do tempo. }\end{array}$ & $\begin{array}{l}\text { Isomorfismo estrutural na } \\
\text { expectativa de sobreviver e ganhar } \\
\text { recursos para ter força política de } \\
\text { definir normas e modelos a serem } \\
\text { seguidos. }\end{array}$ \\
\hline Foco da teoria & 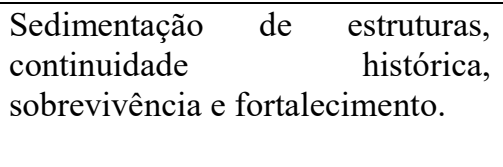 & $\begin{array}{l}\text { Processo de incorporação } \\
\text { modelos institucionais para } \\
\text { legitimação, estabilidade } \\
\text { sobrevivência. }\end{array}$ \\
\hline
\end{tabular}

Fonte: Elaborado pelos autores a partir dos dados (2018).

Os autores do Handbook tratam das organizações como locais tomados por autoridade hierárquica, isto é, o controle é horizontal (de cima para baixo), neste ambiente as normas são específicas e a sobrevivência das organizações depende do seu desempenho e capacidade de se moldar ao ambiente interno e externo. Essas organizações adotam ou não novas regras de acordo com a capacidade destas de fornecer ou melhorar a sua competitividade no mercado

Revista ENIAC Pesquisa, Guarulhos (SP), V.8, n.1, jan.- jun. 2019. 
em que atua, possibilidade de conhecer, vigiar e avaliar a concorrência, ou seja, os incentivos se baseiam na manutenção da vantagem competitiva.

Motta e Vasconcelos (2013b) apontam, na teoria institucional, a organização como o lugar onde ocorre confronto entre várias percepções, grupos e racionalidades (SIMON, 1957apud MARCH, 1993), no qual se objetiva por regras e estrutura, o formato das "soluções" do grupo de influência que prevalece (ZUCKER, 1987 apud MOTTA; VASCONCELOS, 2013b). Assim, o sistema de incentivo apresentado deixa de ser estratégico convencional e passa a serem modelos estratégicos psicossociais, considerando o indivíduo como ator social e a organização, um ambiente de disputa. Exemplos de incentivos são assistências técnicas e de recursos como subsídios, financiamento, reembolso parcial de custos, dentre outros.

O foco da abordagem institucional no Handbook, diz respeito a consolidação e propagação dos processos organizacionais, já que os estudos ainda são bastante heterogêneos, a busca é pela sua sobrevivência e evolução destas ao longo do tempo.

O manual $T G A$, além de ressaltar o intuito de sobrevivência das organizações, também aponta para a importância da busca por recursos, adoção de modelos instituídos em suas estruturas que se estabelecem de forma legítima e atingem a estabilidade. Assim, os resultados obtidos se assemelham ao isomorfismo ou à tendente homogeneidade de formas e estruturas (DIMAGGIO; POWELL, 1991 apud MOTTA; VASCONCELLOS, 2013b).

\section{ANÁlise CRÍTICA DA ABORDAGEM E DOS MANUAIS DE ADMINISTRAÇÃO}

Motta e Vasconcelos (2013b) elencam algumas críticas à abordagem institucionalista. Constatam a separação entre teoria e prática organizacional quando o processo de institucionalização não percorre todas as etapas do processo de legitimação. O comportamento mimético das empresas, com a incorporação de alguns símbolos bem vistos pelas instituições, esvaziado de seu efetivo significado, implica num prejuízo de eficiência técnica.

Os autores apresentam a fragilidade do sistema institucionalizado, comprovado principalmente pela prática de ignorar as infrações às regras formais, uma forma de tolerância aos descumprimentos de regras, que não vista como uma fraude ao sistema ou conduta de máfé (MEYER; ROWAN, 1991 apud MOTTA; VASCONCELOS, 2013b).

Em relação à obra "Teoria Geral da Administração" de Fernando C. Prestes Motta e Isabella Fernando Gouveia de Vasconcelos, apresenta o conteúdo de forma clara e objetiva.

Revista ENIAC Pesquisa, Guarulhos (SP), V.8, n.1, jan.- jun. 2019. 
Quanto às dimensões analisadas, foi identificada a "Delimitação da abordagem e qualidade das referências" para a especificidade do neo-institucionalismo; também com aprofundamento de conteúdo nas dimensões "Histórico-concreta" e a "Teórica".

No entanto, o conteúdo em relação a outras duas dimensões de análise do manual de Motta e Vasconcellos (2013b) não foi encontrado discussão explícita sobre a temática. Assim, foram realizadas interpretações com base nos conteúdos apresentados para os eixos: "Relação entre o capital e trabalho" e "Relação com o sistema capitalista" da dimensão políticoideológica; e da mesma forma a apresentado o entendimento do eixo "Relação entre sujeito e objeto no processo de conhecimento" da dimensão epistemológica, ontológica e gnosiológica.

Os autores do Handbook utilizaram uma vasta quantia de autores para embasar suas discussões, que giraram em torno do processo de consolidação da Teoria Institucional. Este se baseia em alguns passos importantes para o desenvolvimento de instituições como a habitualização, que é o processo de gerar comportamentos diante de problemas organizacionais específicos. Passando pela objetificação, monitoramento dos concorrentes, avaliando as incertezas e os resultados, estruturas testadas por um número maior de organizações geram possibilitam uma avaliação dos custos e benefícios da mesma, o que facilita a sedimentação da estrutura, ou seja, a sua continuidade histórica no decorrer do tempo (TOLBERT; ZUCKER, 2010).

Machado-da-Silva e Gonçalves (2010) reconhecem o trabalho de Tobert e Zucker como uma revisão histórica aliada a dinâmica de institucionalização e mais especificamente os estágios desse processo. Os autores atentam-se a importância do processo do ambiente técnico visando maximizar a eficiência das estruturas onde duas importantes variáveis são a dependência e a incerteza.

Além disso, alguns aspectos importantes para o processo de institucionalização são a diversidade de organizações para as quais determinada estrutura é importante, em que grau esta estrutura exige altos investimentos organizacionais, correlação com os resultados esperados. Neste sentido, a aplicação dessas estruturas por várias organizações torna o processo comparativo relevante, visando avaliar os resultados alcançados o que alavancará as possibilidades de desenvolvimento e propagação dessas estruturas ao longo do tempo (TOLBERT; ZUCKER, 2010).

É necessário que as organizações estejam atentas ao mercado em que estão inseridas, as estruturas utilizadas pelos concorrentes, seu desempenho e o feedback dos indivíduos

Revista ENIAC Pesquisa, Guarulhos (SP), V.8, n.1, jan.- jun. 2019. 
envolvidos, para ganhar competitividade e eficiências visando atingir um estágio completo de institucionalização (TOLBERT; ZUCKER, 2010).

\section{CONSIDERAÇÕES FINAIS}

Observa-se que a abordagem institucionalista foi discutida em ambos manuais analisados, "Handbook de Estudos Organizacionais", organizado por Miguel Caldas, Roberto Fachin e Tânia Fischer e "Teoria Geral da Administração" de Fernando C. Prestes Motta e Isabella Fernando Gouveia de Vasconcelos.

A linguagem clara e objetiva permitiu a facilidade de entendimento da temática, bem como a disposição do conteúdo na delimitação apresentada para a abordagem institucional. No manual de Motta e Vasconcelos, contudo, houve pouco aprofundamento nas discussões em relação à crítica, à dimensão político-ideológica e a epistemologia da pesquisa.

Os autores do Handbook visaram uma abordagem para compreensão do processo de institucionalização, buscaram elementos que poderiam impactar positiva ou negativamente no percurso. Foram considerados fatores organizacionais internos e externos, tais como o sistema social, atores organizacionais e individuais, legislação etc. Todo esse processo visa a dinamizar o processo produtivo, os custos e o desempenho organizacional no mercado em que atua.

No ambiente de intensa competitividade em que as organizações estão inseridas é muito importante que os detentores do poder compreendam a importância de desenvolver sistemas estruturados que possibilitem o ganho de melhores resultados. Os manuais são uma opção acessível àqueles que estão no mercado de trabalho, pois eles compilam diversas visões e reúnem os principais pontos e discussões a respeito de temáticas e teorias importantes para o ambiente organizacional.

Os dois manuais contemplaram a temática, porém o Handbook privilegiou a discussão com dois capítulos específicos para ela o que facilitou a busca e tornou-se um elemento decisivo no momento da sua escolha. Já o manual de Motta e Vasconcelos (2013b) abordou a discussão no capítulo de Teorias Ambientais, a pesquisa poderia ser mais acessível se houvesse menção ao tema no sumário do mesmo.

Revista ENIAC Pesquisa, Guarulhos (SP), V.8, n.1, jan.- jun. 2019. 


\section{REFERÊNCIAS}

BACHMANN, Reinhard; INKPEN, Andrew C. Understanding institutional-based trust building processes in inter-organizational relationships. OrganizationStudies, v. 32, n. 2, p. 281-301, 2011.

BARDIN, L. Análise de conteúdo. São Paulo: Edições 70, 2011.

BERTERO, Carlos Osmar. Organization studies in perspective. Revista de Administração de Empresas, v. 45, n. 1, p. 92-93, 2005.

BRESSER-PEREIRA, Luiz Carlos. O sociólogo das organizações: Fernando C. Prestes Motta. Revista de Administração de Empresas, v. 43, n. 2, p. 116-118, 2003.

CARRER, M. J.; SOUZA FILHO, H. M.; VINHOLIS, M. de M. B. Plural forms of governance in the beef industry: a case study in Brazil. British Food Journal, v. 116, n. 4, p. 643-661, 2014.

CONCEIÇÃO, Octavio Augusto Camargo. O conceito de instituição nas modernas abordagens institucionalistas. Revista de economia contemporânea. Rio de Janeiro. Vol. 6, n. 2 (jul./dez. 2002), p. 119-146, 2002.

CONCEIÇÃO, Octavio Augusto Camargo. O conceito de instituição nas modernas abordagens institucionalistas. Revista de economia contemporânea. Rio de Janeiro. Vol. 6, n. 2 (jul./dez. 2002), p. 119-146, 2002.

COURPASSON, David; REED, Mike. Introduction: Bureaucracy in the age of enterprise. Organization, v. 11, ed. 1, p. 5-12, 2004.

CUNHA, Miguel Pina e. Análise Psicológica, Lisboa, v. 15, n. 1, p. 164-165, mar. 1997.Disponível em <http://www.scielo.mec.pt/scielo.php?script=sci_arttext\&pid=S0870$82311997000100017 \& \operatorname{lng}=$ pt\&nrm=iso $>$. acessos em 15 jan. 2018.

DA SILVA, Vagner Luís. Perspectivas teóricas no Institucionalismo clássico. 2012.

DA SILVA, Zenaide Aparecida; DOS SANTOS, Leonardo Andrade; DOS SANTOS, Silvana Lucia de Andrade. A instituição linguagem formadora da subjetividade do adolescente em conflito com a lei. Revista Constituição e Garantia de Direitos, v. 9, n. 2, p. 23-39, 2017.

LOPES, F. T. Manuais de Administração: Contribuições e Limitações de Teorias em organizações. I Encontro de Ensino e Pesquisa em Administração e Contabilidade, Recife, 2007.

MACHADO-DA-SILVA C. L.; GONÇALVES. S. A. Nota Técnica: A Teoria Institucional. In: Handbook de estudos organizacionais. Org. da edição brasileira: CALDAS, Miguel; FACHIN, Roberto; FISCHER, Tânia. Capital: Atlas, p. 218-225, 2010.

Revista ENIAC Pesquisa, Guarulhos (SP), V.8, n.1, jan.- jun. 2019. 
MARCH, James G. Bounded rationality, ambiguity, and the engineering of choice. Economics and Psychology. England/USA: Edward Elgar, p. 249-270, 1993.

MARCH, James. G. Introdução. In: Handbook of organizations. Nova York: Routledge, p. ix-xvi, 2013.

MEYER, John W.; ROWAN, Brian. Institutionalized Organizations: Formal Struct11re as Myth and Ceremony”. American journal of Sociology, v. 83, n. 2, p. 340-363, 1977.

MORETTO, Cybele Carolina; TERZIS, Antonios. O sofrimento nas instituições e possibilidades de intervenção grupal. Arq. bras. psicol., Rio de Janeiro , v. 62, n. 3, p. 4247, 2010

Disponível

em

$<$ http://pepsic.bvsalud.org/scielo.php?script=sci_arttext\&pid=S1809-

$52672010000300006 \& \operatorname{lng}=$ pt\&nrm=iso $>$. acesso em 19 jan. 2018.

MOTTA, Fernando Cláudio Prestes; VASCONCELOS, Isabella Gouveia de. Introdução. In:Teoria geral da administração. São Paulo: Cengage Learning, ed. 3, p. XIII-XIX e 3-21, 2013a.

Fernando Cláudio Prestes; VASCONCELOS, Isabella Gouveia de. O NeoInstitucionalismo (The New Institutionalism). In: Teoria geral da administração. São Paulo: Cengage Learning, ed. 3, p. 382-398, 2013b.

NORTH, Douglass C. Institutions. Journal of economic perspectives, v. 5, n. 1, p. 97-112, 1991.

PAULA, Ana Paula Paes de. Fernando Prestes Motta: em busca de uma abordagem psicanalítica das organizações. Organizações \& Sociedade, v. 12, n. 34, p. 13-15, 2005.

PAULON, Simone Mainieri. Instituição e intervenção institucional: percurso conceitual e percalços metodológicos. Mnemosine, v. 5, n. 2, 2009.

PEREIRA, William Cesar Castilho. Movimento institucionalista: principais abordagens. Estudos e pesquisas em psicologia, v. 7, n. 1, p. 10-19, 2007.

PIMENTEL, T. D. et al. Espelho, espelho meu me diga que teoria sou eu. Revista de Administração da FEAD-Minas, v 3, n. 2, 2006.

SCOTT, W. Richard. Instituitions and organizations. Thousande Oakes: Sage, 2001.

SCOTT, W. Richard. Institutions and organizations: Ideas, interests, and identities. Sage Publications, 2013.

TOLBERT, P. S.; ZUCKER, L. G. A Institucionalização da Teoria Institucional. In: Handbook de estudos organizacionais. Org. da edição brasileira: CALDAS, Miguel; FACHIN, Roberto; FISCHER, Tânia. Capital: Atlas, p. 194-217, 2010.

Revista ENIAC Pesquisa, Guarulhos (SP), V.8, n.1, jan.- jun. 2019. 
WILLIAMSON, O. E. Calculativeness, trust, and economic organization. The Journal of Law and Economics, v. 36, n. 1, Part 2, p. 453-486, 1993.

WILLIAMSON, O. E. The new institutional economics: taking stock, looking ahead. Journal of economic literature, v. 38, n. 3, p. 595-613, 2000.

ZYLBERSZTAJN, Decio; ZUURBIER, Peter. A non-naïve explanation of trust: avoiding mistaken decisions for agribusiness chain management. In: IAMA Agribusiness Forum\&Congress, Florence, Italy. 1999. 